\title{
Relationship between morphological changes and endotoxin release induced by carbapenems in Pseudomonas aeruginosa
}

\author{
TOSHINOBU HORII, SATOSHI ICHIYAMA*, MICHIO OHTA and MIYA KOBAYASHI†
}

Departments of Bacteriology and †Anatomy, Nagoya University School of Medicine, 65 Tsurumai-cho, Showaku, Nagoya 466 and *Department of Clinical Laboratory Medicine, Kyoto University Hospital, 54 Kawahara-cho, Sakyo-ku, Kyoto 606, Japan

\begin{abstract}
The relationship between morphological changes and endotoxin release induced in vitro by carbapenems in a clinical isolate of Pseudomonas aeruginosa was examined. The time-course and magnitude of endotoxin release induced varied among imipenem, panipenem, meropenem and biapenem and related to the morphological changes caused by these agents which variously affected cell shape, cell-wall disintegration and cell lysis. The amount of endotoxin released by carbapenem-treated cells correlated with both the cell-wall morphology and bacterial shape immediately before lysis. Meropenem and biapenem caused markedly increased endotoxin release during cell lysis and cell-wall disintegration, whereas imipenem and panipenem caused much less release of endotoxin.
\end{abstract}

\section{Introduction}

Endotoxin is a component of the outer membrane of gram-negative bacteria and its release from the bacterial cell wall is an important factor in sepsis during gram-negative infections. Septic shock and endotoxaemia may occur during antibiotic therapy for gram-negative infections, with the antibiotic promoting the endotoxin release, and may be related to a worsening of the clinical symptoms [1-5]. Pathogens for which antibiotic-induced endotoxin release is a clinical problem include Escherichia coli, Klebsiella pneumoniae, Pseudomonas aeruginosa, Haemophilus influenzae type $\mathrm{b}$ and Neisseria meningitidis [1, 2, 6-9].

The amount of endotoxin release induced by a $\beta$ lactam antibiotic relates in part to the affinity of the drug for the penicillin-binding proteins (PBPs) [8-11]. PBPs are responsible for the synthesis, shape and integrity of the bacterial cell wall, and antibiotics with identical minimum inhibitory concentrations (MICs) but differing PBP specificities may induce different changes in cell morphology, leading to the release of

Received 14 April 1998; revised version received 5 July 1998; accepted 8 July 1998.

Corresponding author: Dr T. Horii. different amounts of endotoxin [10,12]. Among the carbapenems, imipenem, panipenem and biapenem have preferential affinity for PBP-2 of $P$. aeruginosa and cause conversion of the bacilli to round cells, with the release of a relatively small amount of endotoxin [13-15]. By contrast, meropenem has a very high affinity for both PBP-2 and PBP-3 of $P$. aeruginosa and causes the formation of filamentous cells with a central oval swelling and leads to the release of larger amounts of endotoxin [16]. Ceftazidime binds primarily to PBP-3 of $P$. aeruginosa, resulting in filamentation and the ultimate release of a large amount of endotoxin [15].

Although different carbapenems induce different morphological changes [17], data on the relationship between endotoxin release and morphological characteristics are limited and some reports have shown that antibiotic-induced endotoxin release is also correlated with cell-wall breakage and cell lysis [18]. To evaluate the effect of carbapenems on bacterial cell-wall morphology and endotoxin release, the correlation between the amount of endotoxin release and morphological changes of $P$. aeruginosa exposed to the different carbapenems over various time periods were investigated. The morphology of the cell shape and the cell wall were observed by phase-contrast microscopy and transmission electron microscopy. The study attempted to identify morphological changes that related to increased endotoxin release. 


\section{Materials and methods}

\section{Bacterial strains and culture media}

Twenty clinical isolates of $P$. aeruginosa were used. These had been stored at $-70^{\circ} \mathrm{C}$ in Luria-Bertani broth (LB; Difco Laboratories, Detroit, MI, USA) containing glycerol $20 \%$. Before use, the bacteria were grown overnight at $37^{\circ} \mathrm{C}$ on LB agar plates.

\section{Antibiotics}

The effects of the following antibiotics were investigated: ceftazidime (Glaxo, Tokyo, Japan), imipenem (Banyu, Tokyo, Japan), panipenem (Sankyo, Tokyo, Japan), meropenem (Sumitomo, Osaka, Japan) and biapenem (Lederle, Tokyo, Japan).

\section{Susceptibility testing}

MICs were determined by dilution testing on MuellerHinton agar (Difco) [19]. A 5- $\mu$ l inoculum, containing c. $10^{6} \mathrm{cfu} / \mathrm{ml}$ of logarithmic phase cells grown in Mueller-Hinton Broth (Difco) was used. Plates were incubated at $37^{\circ} \mathrm{C}$ overnight.

\section{Morphological studies}

Portions of one colony were inoculated into 5-ml amounts of Mueller-Hinton broth and cultured at $37^{\circ} \mathrm{C}$ overnight. Portions of these cultures $(5 \mu \mathrm{l}$; with $c$. $\left.10^{6} \mathrm{cfu} / \mathrm{ml}\right)$ were placed on to Mueller-Hinton agar containing the appropriate antibiotics at $0.5 \times \mathrm{MIC}$ and incubated at $37^{\circ} \mathrm{C}$ for $1.5,3,4.5$ or $6 \mathrm{~h}$. Each preparation was fixed with Karnovsky's fixative (paraformaldehyde $2 \%$ and glutaraldehyde $2.5 \%$ in $0.05 \mathrm{M}$ phosphate buffer, $\mathrm{pH} 7.4$ ) and the morphology of the $P$. aeruginosa isolates was evaluated by phase-contrast microscopy on a wet mount.

\section{Endotoxin release studies}

Glass test tubes were heated at $250^{\circ} \mathrm{C}$ for $3 \mathrm{~h}$ to ensure that they were endotoxin-free; otherwise sterile endotoxin-free plastic specimen containers and pipette tips were used for all assays. Bacteria were inoculated into Mueller-Hinton broth and incubated at $37^{\circ} \mathrm{C}$ for $5 \mathrm{~h}$, then diluted 1000 -fold into $10-\mathrm{ml}$ amounts of fresh Mueller-Hinton broth and incubated at $37^{\circ} \mathrm{C}$ for $1.5,3$, 4.5 and $6 \mathrm{~h}$ in the presence of antibiotics at $0.5 \times$ MIC. The amount of bacterium-free LPS in these samples was determined after removing bacteria (and their bound LPS) by filtration through endotoxin-free $0.45 \mu \mathrm{m}$ pore cellulose ester filters (Millex-HA, Millipore, Tokyo, Japan) [10]. The filtrates were immediately stored at $-70^{\circ} \mathrm{C}$. To quantify the bacteria, samples were serially diluted in phosphate-buffered

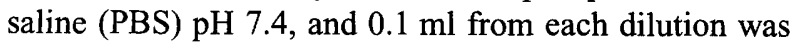
plated on to Mueller-Hinton agar. Colonies were counted after overnight incubation at $37^{\circ} \mathrm{C}$.

\section{Endotoxin assays}

Endotoxin activity was determined by a specific chromogenic assay with the Limulus coagulation enzyme (ES Test, Seikagaku-Kogyo, Tokyo, Japan). Endotoxin concentrations were calculated by comparison with the reference endotoxin from $E$. coli O111:B4. The samples and reference endotoxin were serially diluted from 1 in 1 to 1 in $10^{6}$ in endotoxinfree physiological saline (Otsuka, Tokyo, Japan) to achieve concentrations in the range $0.01-0.5 \mathrm{ng} / \mathrm{ml}-$ a range wherein the assay gives a linear relationship between $E$. coli endotoxin O111:B4 concentration and spectrophotometric absorbance [20].

\section{Transmission electron microscopy}

P. aeruginosa NU10 was cultured for various time periods at $37^{\circ} \mathrm{C}$ in Mueller-Hinton broth containing the appropriate antibiotics at $0.5 \times \mathrm{MIC}$. The bacteria then were collected by centrifugation and treated with Karnovsky's fixative at $4^{\circ} \mathrm{C}$ for $48 \mathrm{~h}$. These samples were then rinsed with $0.1 \mathrm{M}$ PBS and stained with osmium tetroxide $1 \%$ in $0.1 \mathrm{M}$ cacodylate buffer, $\mathrm{pH}$ 7.4 , at room temperature for $90 \mathrm{~min}$. After rinsing with $0.1 \mathrm{M}$ PBS, they were dehydrated for 15 -min periods in increasing concentrations of ethanol $(70,80,90,95$ and $100 \% \mathrm{v} / \mathrm{v}$ ) and embedded in a Quetol mixture (Nissin EM, Tokyo, Japan). Sections were cut with a diamond knife on a Porter-Blum MT6000 ultramicrotome (RMC, Tucson, AZ, USA) and were stained with uranyl acetate $1 \%$ for $20 \mathrm{~min}$, followed by a lead staining reagent (Katayama Chemical Industries, Osaka, Japan) for $2 \mathrm{~min}$. The sections were examined with a transmission electron microscope (Hitachi H-7100, Hitachi, Tokyo, Japan).

\section{Statistical analysis}

Paired data were compared by the two-tailed paired Student's $t$ test; $p$ values of $<0.05$ were considered significant.

\section{Results}

\section{Antibiotic susceptibility}

$P$ aeruginosa NU10 was sensitive to ceftazidime (MIC $2 \mathrm{mg} / \mathrm{L}$ ), imipenem (MIC, $4 \mathrm{mg} / \mathrm{L}$ ), meropenem (MIC, $1 \mathrm{mg} / \mathrm{L})$ and biapenem $(1 \mathrm{mg} / \mathrm{L})$ but not to panipenem (MIC, $16 \mathrm{mg} / \mathrm{L}$ ) [19].

\section{Changes in the morphology of antibiotic-treated P. aeruginosa NU10}

Among the 20 clinical isolates investigated, the morphological changes induced by the antibiotics were most variable for $P$. aeruginosa NU10 (Fig. 1) [17]. For this organism imipenem and panipenem induced sphaeroplast formation from 1.5 to $3 \mathrm{~h}$, then ovoid cell formation or lysis from 3 to $6 \mathrm{~h}$. Meropenem and 


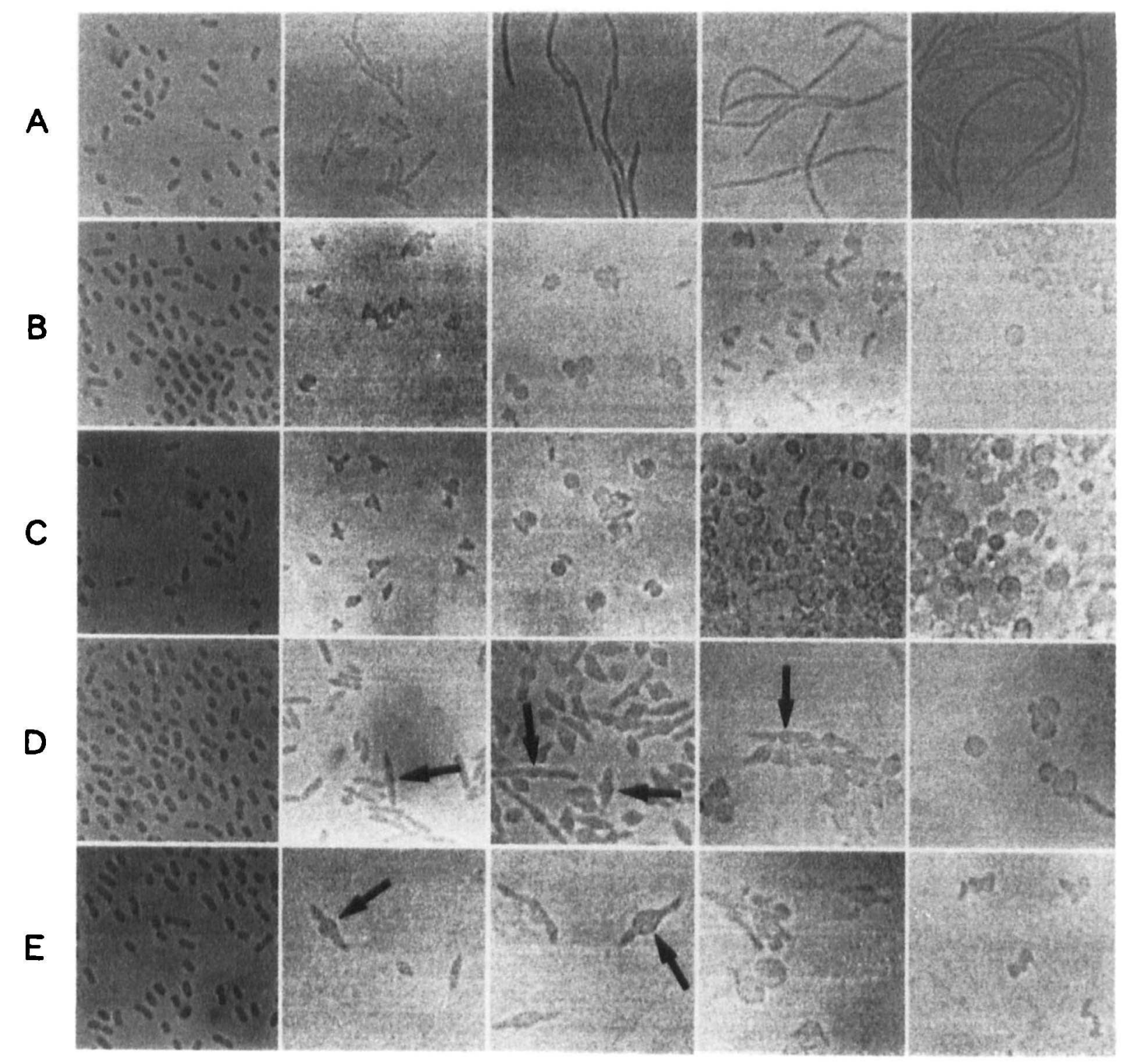

$5 \mu \mathrm{m}$

Fig. 1. Phase-contrast micrographs of $P$ aeruginosa NU10 cells exposed to: A, ceftazidime for $0,1.5,3,4.5$ and $6 \mathrm{~h}$ $\left(\mathrm{A}_{1}, \mathrm{~A}_{2}, \mathrm{~A}_{3}, \mathrm{~A}_{4}\right.$ and $\mathrm{A}_{5}$, respectively); $\mathrm{B}$, imipenem for $0,1.5,3,4.5$ and $6 \mathrm{~h}\left(\mathrm{~B}_{1}, \mathrm{~B}_{2}, \mathrm{~B}_{3}, \mathrm{~B}_{4}\right.$ and $\left.\mathrm{B}_{5}\right)$; $\mathrm{C}$, panipenem for $0,1.5,3,4.5$ and $6 \mathrm{~h}\left(\mathrm{C}_{1}, \mathrm{C}_{2}, \mathrm{C}_{3}, \mathrm{C}_{4}\right.$ and $\left.\mathrm{C}_{5}\right)$; $\mathbf{D}$, meropenem for $0,1.5,3,4.5$ and $6 \mathrm{~h}\left(\mathrm{D}_{1}, \mathrm{D}_{2}, \mathrm{D}_{3}, \mathrm{D}_{4}\right.$ and $\left.\mathrm{D}_{5}\right) ; \mathbf{E}$, biapenem for $0,1.5,3,4.5$ and $6 \mathrm{~h}\left(\mathrm{E}_{1}, \mathrm{E}_{2}, \mathrm{E}_{3}, \mathrm{E}_{4}\right.$ and $\left.\mathrm{E}_{5}\right)$. The antibiotics were used at $0.5 \times \mathrm{MIC}$. Arrows indicate cells with central ovals. Bar $=5 \mu \mathrm{m}$.

biapenem caused formation of elongated cells with swollen oval centres, with meropenem mainly inducing elongation, while biapenem predominantly induced ovoid formation. Meropenem induced formation of filaments with one or more oval centres from 1.5 to $4.5 \mathrm{~h}$, and this was followed by cell lysis from 4.5 to $6 \mathrm{~h}$; biapenem induced the formation of cells with single large oval centres from 1.5 to $3 \mathrm{~h}$, with lysis from 3 to $6 \mathrm{~h}$. Ceftazidime caused the formation of long filaments.
Viable counts and endotoxin release

Exposure to ceftazidime and to all the carbapenems except panipenem reduced the viable cell count of $P$. aeruginosa NU10, whereas the cell count continued to increase in the presence of panipenem (Fig. 2a). The time-courses of endotoxin release are shown in Fig. $2 b$.

The amount of endotoxin released from $P$. aeruginosa NU10 after exposure to imipenem and panipenem 
a

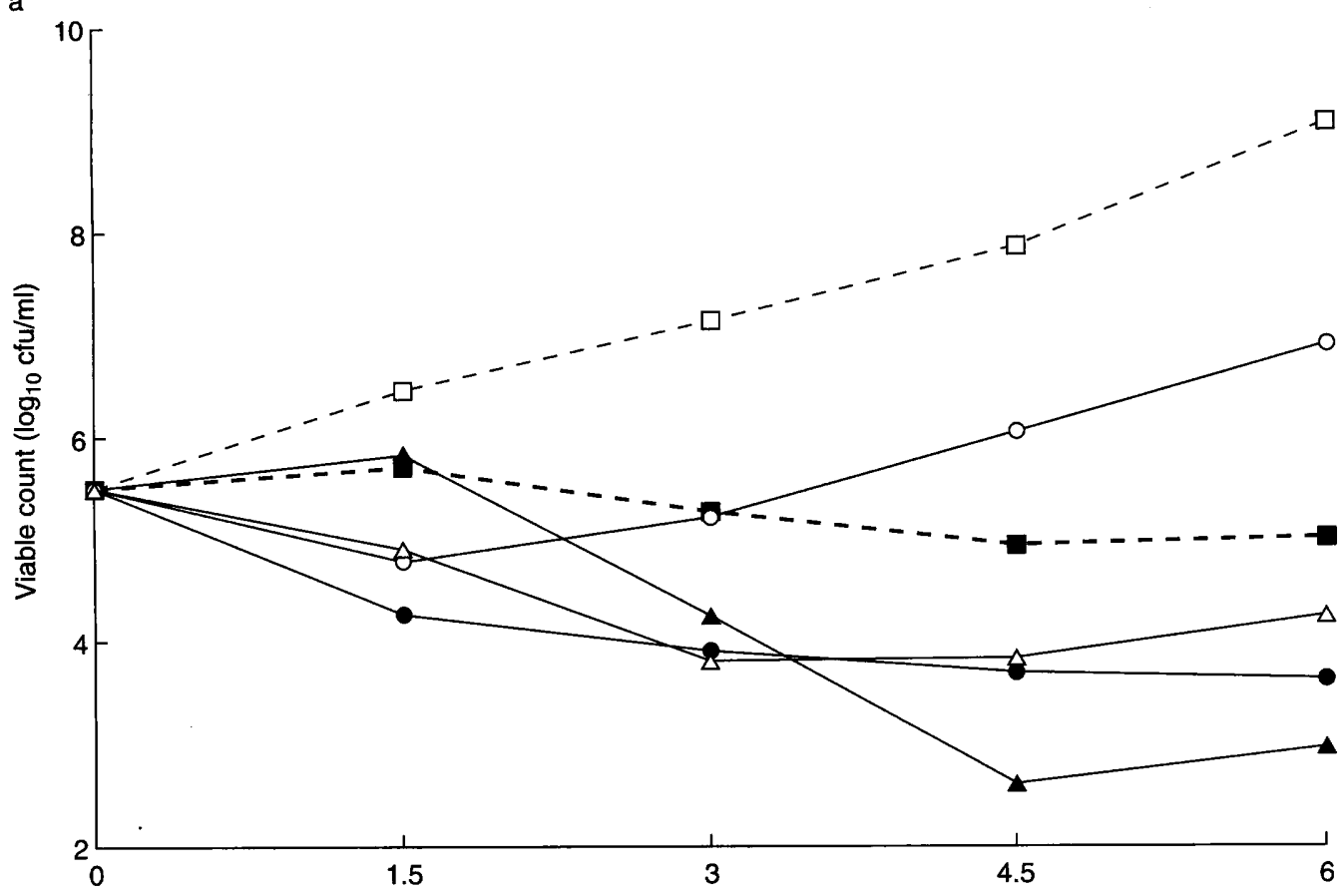

b

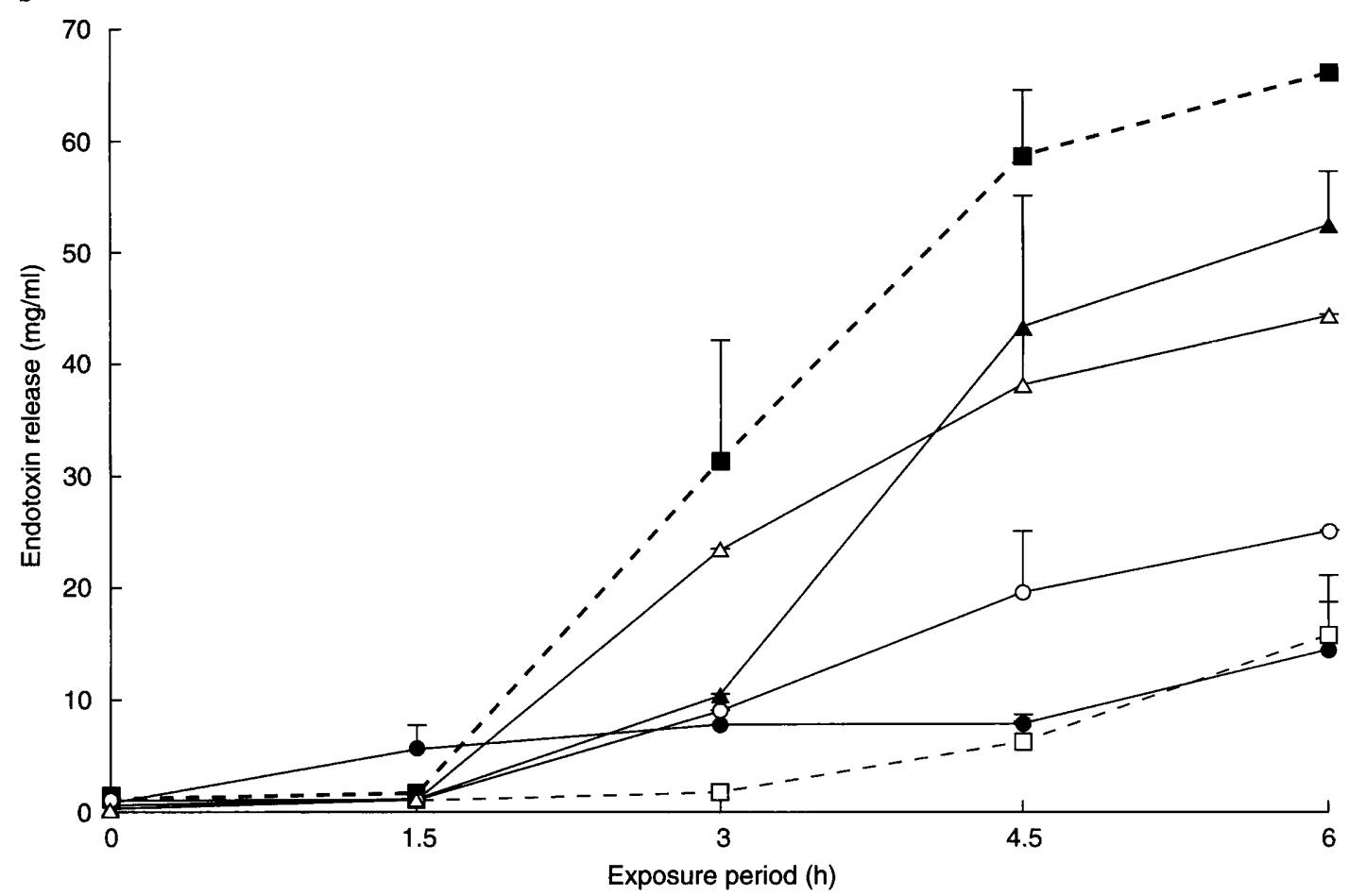

Fig. 2. Effect of ceftazidime and carbapenems at $0.5 \times \mathrm{MIC}$ on (a) growth (cfu/ml), (b) release of endotoxin from $P$. aeruginosa $\mathrm{NU} 10(\mathrm{mg} / \mathrm{ml})$, bar $=\mathrm{SE}$. Each antibiotic was added at time zero: ceftazidime - - , impenem - - , panipenem $-\mathrm{O}_{-}$, meropenem $-\mathbf{\Lambda}$, biapenem $-\triangle-$; no antibiotics were added to the control culture $-\square-$. Each panel shows the mean data from three separate experiments.

remained low throughout the 6-h observation period; imipenem induced the greatest amount of endotoxin release after exposure for $1.5-\mathrm{h}$, but the endotoxin release induced by panipenem after $3-6 \mathrm{~h}$ was higher than with imipenem. The amount of endotoxin released during the first $3 \mathrm{~h}$ of exposure to meropenem was similar to that during the first $3 \mathrm{~h}$ of treatment with imipenem and panipenem, but there was much greater subsequent endotoxin release with meropenem, with an abrupt increase after $3-4.5 \mathrm{~h}$ of exposure and with the amount of endotoxin release ultimately approaching that induced by ceftazidime. Biapenem 

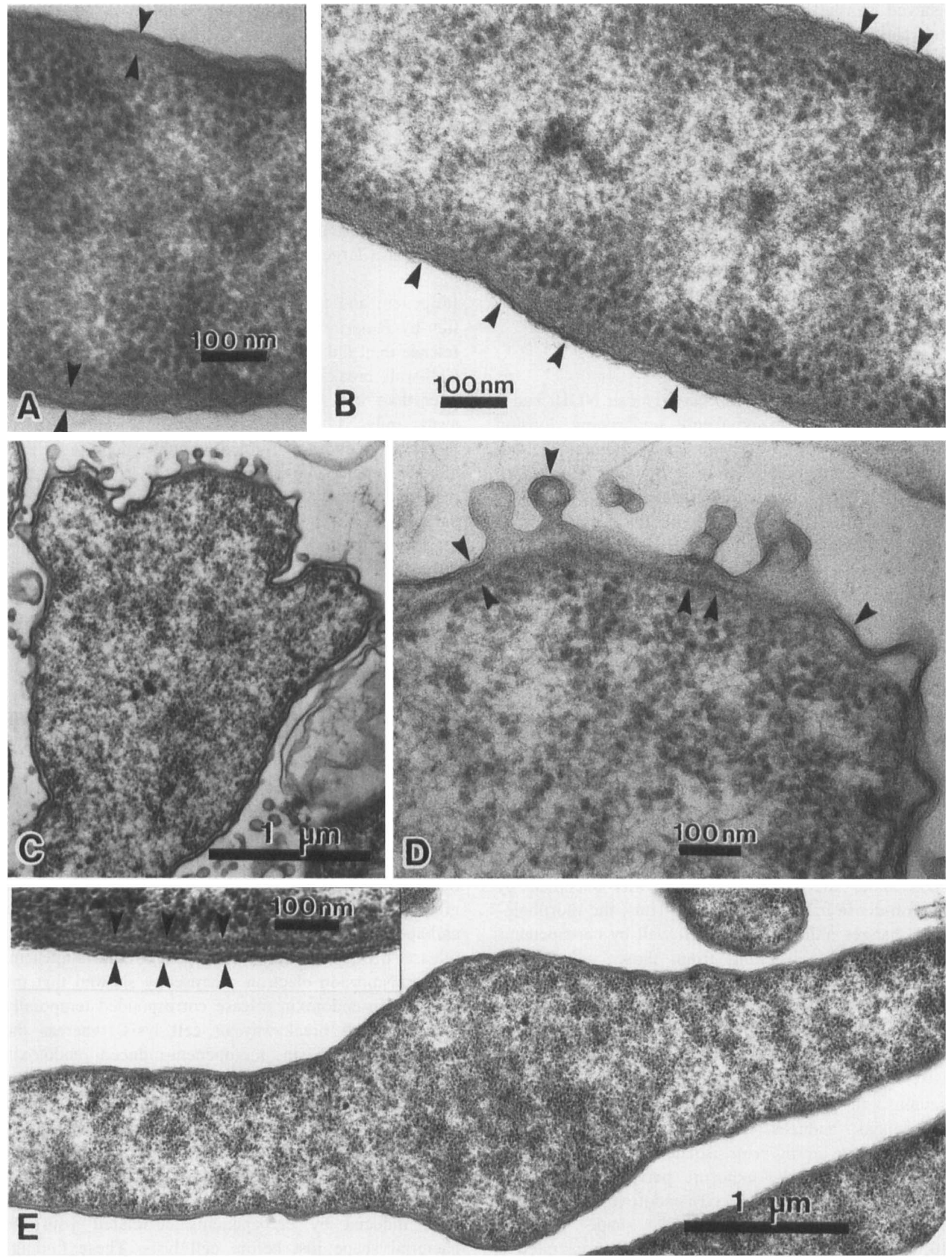

Fig. 3. Transmission electron micrographs of $P$. aeruginosa NU10 exposed to carbapenems and ceftazidime. A, Untreated cells, showing the cell wall and cell membrane; arrowheads indicate a high magnification profile of the intact double membrane. B, Cells exposed to ceftazidime, with marked elongation and dense material under the outer membrane. C, Biapenem-treated cells after exposure for $3 \mathrm{~h}$, with central ovals and cell-wall breakaway. D, Cell-wall breakaway of biapenem-treated cells, with separation of the outer membrane from the cytoplasmic membrane (arrowheads) and with parts of the outer membrane budding off. E, Meropenem-treated cells after exposure for $3 \mathrm{~h}$, showing elongation but no cell-wall breakaway or lysis; the inset in the top left of panel $\mathrm{E}$ shows a high magnification profile of the cell surface (arrowheads) of these meropenem-treated cells. 
behaved similarly to meropenem, but with an early and marked increase in endotoxin release between 1.5 and $3 \mathrm{~h}$ of exposure. Ceftazidime induced the largest amount of endotoxin release during the entire 6-h observation period. Endotoxin release was greater after 4.5-6 h of treatment with meropenem, biapenem and ceftazidime than with imipenem or panipenem, and there was no significant difference in the amount of endotoxin release among bacteria treated with meropenem, biapenem or ceftazidime after exposure for this period. None of the antibiotics had any effect on the Limulus assay (data not shown).

\section{Transmission electron microscopy of antibiotic- treated P. aeruginosa NU10}

Before $\beta$-lactam treatment, $P$. aeruginosa NU10 had a bacillary shape, with some cells undergoing division (data not shown). Both the outer membrane and cytoplasmic membranes were prominent (Fig. 3A). Marked cell-wall 'breakaway' (separation of the outer membrane from the cytoplasmic membrane, sometimes with outer-membrane fragments budding off) and cell lysis were observed $1.5 \mathrm{~h}$ after exposure of bacteria to imipenem, but minimal cell-wall breakaway was observed after exposure to panipenem for $1.5 \mathrm{~h}$ (data not shown). After $3 \mathrm{~h}$ of biapenem treatment, the cells with central oval swellings showed cell-wall 'breakaway' and cell lysis (Fig. 3C and D). After $3 \mathrm{~h}$ of meropenem treatment, cell elongation without cell-wall breakaway was predominant (Fig. 3E), whereas cell lysis was frequent after exposure for $4.5 \mathrm{~h}$ (data not shown). Ceftazidime caused marked cell elongation, but the bilaminar structure of the outer and cytoplasmic membranes was not prominent. Furthermore, the cytoplasmic membrane was not clearly visible and the space under the outer membrane was occupied by electron-dense material (Fig. 3B). Thus, the morphological changes induced in the cell wall by carbapenems were obviously different from those induced by ceftazidime.

\section{Discussion}

Previous in-vitro studies have shown that each carbapenem induces characteristic morphological changes in $P$. aeruginosa isolates depending on its concentration and the exposure period $[10,15]$. The degree of antibiotic-induced endotoxin release is associated with the bacterial shape induced $[10,12,15,18,21]$. An earlier study demonstrated a wide variety of morphological changes in clinical $P$. aeruginosa isolates exposed to carbapenems [17] and this study showed that, for $P$. aeruginosa NU10, the extent of carbapenem-induced endotoxin release correlated with these changes, affecting cell shape, cell-wall breakaway and cell lysis during the time-course of incubation. Exposure to meropenem or biapenem resulted in release of much more endotoxin than did exposure to imipenem and panipenem. Biapenem markedly increased endotoxin release before cell lysis and this effect was associated with cell elongation and cell-wall breakaway. Meropenem accelerated the release of endotoxin from 3 to $4.5 \mathrm{~h}$, in association with cell elongation and cell lysis, but without cell-wall breakaway. These results suggest that the factors that influence endotoxin release differ among the carbapenems. Neither cell-wall breakaway nor cell lysis was observed during exposure to ceftazidime for $6 \mathrm{~h}$, although a large amount of endotoxin was released.

Imipenem and panipenem caused sphaeroplast formation by $P$. aeruginosa NU10 and caused less endotoxin release than did the other carbapenems or ceftazidime. Cell-wall breakaway induced by panipenem occurred later than with imipenem. The early cell-wall breakaway induced by imipenem resulted in an early increase in endotoxin release, but endotoxin release after treatment with panipenem for 3-6h was greater than with imipenem. The endotoxin release seen with panipenem may be material spontaneously released by regrowing bacteria, as reported in previous studies $[10,15,22]$, and it should be noted that the MIC of panipenem was high and the bacterial count increased during exposure to the drug for 1.5-6h. However, although the bacterial count increased by about an order of magnitude during $6 \mathrm{~h}$ of exposure to panipenem (Fig. 2a), the photographs in Fig. $1\left(C_{1}\right.$ and $\mathrm{C}_{5}$ ) indicate that the bacterial structures were compromised by treatment with panipenem. It could be postulated that these structural alterations induced by panipenem were reversible, whereas, with the other carbapenems, they are not.

Meropenem and biapenem both caused the formation of elongated cells with a central oval and induced greater release of endotoxin after $6 \mathrm{~h}$ than the other carbapenems. However, the time-course of endotoxin release differed between meropenem and biapenem, and transmission electron microscopy showed that the increase in endotoxin release corresponded temporally with cell-wall breakaway or cell lysis, whereas the marked increase in meropenem-induced endotoxin release was associated with the abrupt lysis of cells with central ovals and was not linked to cell-wall breakaway. Thus, increases in endotoxin release were associated with morphological changes in cell-wall breakaway, as well as bacterial shape, before the lysis occurred. The amount of endotoxin released after cell lysis induced by carbapenems correlated with the bacterial shape just before cell lysis. These findings suggest that observation of morphological changes just before cell lysis may be useful in predicting the likely extent of carbapenem-induced endotoxin release.

We thank the members of the Equipment Centre for Research and Education, Nagoya University School of Medicine for their technical support and Keiko Shimamoto for assistance. This work was supported in part by a grant from the Ministry of Healthy and Welfare of Japan. 


\section{References}

1. Shenep JL, Flynn PM, Barrett FF et al. Serial quantitation of endotoxemia and bacteremia during therapy for Gram-negative bacterial sepsis. J Infect Dis 1988; 157: 565-568.

2. Hurley JC. Antibiotic-induced release of endotoxin: a reappraisal. Clin Infect Dis 1992; 15: 840-854.

3. Leibovici L, Drucker M, Konigsberger H et al. Septic shock in bacteremic patients: risk factors, features and prognosis. Scand $J$ Infect Dis 1997; 29: 71-75.

4. Mock CN, Jurkovich GJ, Dries D, Maier RV. The clinical significance of endotoxin released by antibiotics: what is the evidence? J Endotoxin Res 1996; 3: 253-259.

5. Morrison DC, Bucklin SE. Evidence for antibiotic-mediated endotoxin release as a contributing factor to lethality in experimental Gram-negative sepsis. Scand J Infect Dis 1996; Suppl 101: 3-8.

6. Arditi M, Ables L, Yogev R. Cerebrospinal fluid endotoxin levels in children with $H$. influenzae meningitis before and after administration of intravenous ceftriaxone. $J$ Infect Dis 1989; 160: 1005-1011.

7. Hurley JC, Louis WJ, Tosolini FA, Carlin JB. Antibioticinduced release of endotoxin in chronically bacteriuric patients. Antimicrob Agents Chemother 1991; 35: 2388-2394.

8. Dofferhoff ASM, Nijland JH, de Vries-Hospers HG, Mulder POM, Weits J, Bom VJJ. Effects of different types and combinations of antimicrobial agents on endotoxin release from Gram-negative bacteria: an in-vitro and in-vivo study. Scand $J$ Infect Dis 1991; 23: 745-754.

9. Prins JM, van Agtmael MA, Kuijper EDJ, van Deventer SJH, Speelman P. Antibiotic-induced endotoxin release in patients with gram-negative urosepsis: a double-blind study comparing imipenem and ceftazidime. $J$ Infect Dis 1995; 172: 886-891.

10. Jackson JJ, Kropp H. $\beta$-lactam antibiotic-induced release of free endotoxin: in vitro comparison of penicillin-binding protein (PBP) 2-specific imipenem and PBP 3-specific ceftazidime. J Infect Dis 1992; 165: 1033-1041.

11. Prins JM, van Deventer SJH, Kuijper EJ, Speelman P. Clinical relevance of antibiotic-induced endotoxin release. Antimicrob Agents Chemother 1994; 38: 1211-1218.

12. Eng RHK, Smith SM, Fan-Havard P, Ogbara T. Effect of antibiotics on endotoxin release from gram-negative bacteria. Diagn Microbiol Infect Dis 1993; 16: 185-189.

13. Ohya S, Utsui Y, Yajima T et al. Microbiological evaluation of panipenem/betamipron, a new parenterally active carbapenem II. Mechanism of antibacterial activity of panipenem. Chemotherapy 1991; 39 Suppl 3: 102-110.

14. Nishino $\mathrm{T}$, Otsuka $\mathrm{M}$, Obana $\mathrm{Y}$ et al. In vitro and in vivo antibacterial activity of biapenem, a new carbapenem antibiotic. Chemotherapy 1994; 42 Suppl 4: 64-84.

15. Jackson JJ, Kropp H. Differences in mode of action of $\beta$ lactam antibiotics influence morphology, LPS release and in vivo antibiotic efficacy. $J$ Endotoxin Res 1996; 3: 201-218.

16. Sumita Y, Tada E, Nouda H, Okuda T, Fukusawa M. Mode of action of meropenem, a new carbapenem antibiotic. Chemotherapy 1992; 40 (S-1): 90-102.

17. Horii T, Kobayashi M, Sato K, Ichiyama S, Ohta M. An in vitro study of carbapenem-induced morphological changes and endotoxin release in clinical isolates of Gram-negative bacilli. $J$ Antimicrob Chemother 1998; 41: 435-442.

18. Crosby HA, Bion JF, Penn CW, Elliott TSJ. Antibiotic-induced release of endotoxin from bacteria in vitro. $J$ Med Microbiol 1994; 40: $23-30$.

19. National Committee for Clinical Laboratory Standards. Methods for dilution antimicrobial susceptibility testing for bacteria that grow aerobically, 2nd edn. Approved Standard M7-A3. Villanova, PA, NCCLS. 1993.

20. Obayashi T, Tamura H, Tanaka S, Ohki M, Takahashi S, Kawai T. Endotoxin-inactivating activity in normal and pathological human blood samples. Infect Immun 1986; 53: 294-297.

21. Dofferhoff ASM, Buys J. The influence of antibiotic-induced filament formation on the release of endotoxin from Gramnegative bacteria. $J$ Endotoxin Res 1996; 3: 187-194.

22. Cadieux JE, Kuzio J, Milazzo FH, Kropinski AM. Spontaneous release of lipopolysaccharide by Pseudomonas aeruginosa. $J$ Bacteriol 1983; 155: 817-825. 